\title{
Efficacy of an imidacloprid/flumethrin collar against fleas, ticks and tick-borne pathogens in dogs
}

Filipe Dantas-Torres ${ }^{1,2}$, Gioia Capelli ${ }^{3}$, Alessio Giannelli ${ }^{1}$, Rafael Antonio Nascimento Ramos ${ }^{1}$, Riccardo Paolo Lia ${ }^{1}$, Cinzia Cantacessi ${ }^{4}$, Donato de Caprariis ${ }^{1}$, Anna Sara De Tommasi ${ }^{1}$, Maria Stefania Latrofa', Vita Lacasella', Viviana Domenica Tarallo ${ }^{1}$, Giancarlo Di Paola ${ }^{1}$, Barbara Qurollo ${ }^{5}$, Edward Breitschwerdt ${ }^{5}$, Dorothee Stanneck ${ }^{6}$ and Domenico Otranto ${ }^{1 *}$

\begin{abstract}
Background: Tick-borne diseases comprise a group of maladies that are of substantial medical and veterinary significance. A range of tick-borne pathogens, including diverse species of bacteria and protozoa, can infect both dogs and humans. Hence, the control of tick infestations is pivotal to decrease or prevent tick-borne pathogen transmission. Therefore, different commercial products with insecticidal, repellent or both properties have been developed for use on dogs. Recently, a collar containing a combination of imidacloprid 10\% and flumethrin $4.5 \%$ has proven effective to prevent tick and flea infestations in dogs under field conditions and the infection by some vector-borne pathogens they transmit under laboratory-controlled conditions.
\end{abstract}

Methods: From March 2011 to April 2012, a field study was conducted in a private shelter in southern Italy to assess the efficacy of the imidacloprid/flumethrin collar against tick and flea infestations and to determine if this strategy would decrease tick-borne pathogen transmission in young dogs. A total of 122 animals were enrolled in the study and randomly assigned to group A ( $n=64$; collared) or group B ( $n=58$; untreated controls). Dogs were examined monthly for ticks and fleas and systematically tested for selected tick-borne pathogens.

Results: Compared to controls, the collar provided overall efficacies of $99.7 \%$ and 100\% against tick and flea infestation, respectively. The overall efficacy for the prevention of tick-borne pathogens (i.e., Anaplasma platys and Babesia vogeli) was $91.6 \%$.

Conclusions: This study demonstrates that the imidacloprid/flumethrin collar is efficacious against flea and tick infestation as well as tick-borne pathogen transmission to dogs under field conditions.

Keywords: Canine vector-borne diseases, Anaplasma platys, Babesia vogeli, Hepatozoon canis, Prevention, Dog, Imidacloprid, Flumethrin, Tick

\section{Background}

Tick-borne diseases (TBDs) comprise a group of illnesses caused by numerous pathogens (e.g., viruses, bacteria, protozoa, and helminths) that may be transmitted by a number of tick species [1]. These diseases may range from subclinical to life-threatening conditions, with the severity of clinical signs depending on the microorganism(s) involved and the host immune

\footnotetext{
* Correspondence: domenico.otranto@uniba.it

'Department of Veterinary Medicine, University of Bari, Bari, Valenzano, Italy Full list of author information is available at the end of the article
}

response against the infection [2,3]. Importantly, some pathogens transmitted by certain tick species belonging to the Rhipicephalus sanguineus group are primarily found in association with dogs, but may potentially infect humans, as is the case of Ehrlichia canis, Rickettsia conorii, Rickettsia massiliae, and Rickettsia rickettsii [1]. These observations highlight the importance of controlling tick infestations in dogs, so as to reduce the risk of tick-borne infections in pets and family members.

The Mediterranean region provides a suitable environment for the development of a range of tick species,

\section{Biomed Central}

(c) 2013 Dantas-Torres et al.; licensee BioMed Central Ltd. This is an Open Access article distributed under the terms of the Creative Commons Attribution License (http://creativecommons.org/licenses/by/2.0), which permits unrestricted use, distribution, and reproduction in any medium, provided the original work is properly cited. 
which infest dogs throughout the year. Consequently, some TBD-causing pathogens (e.g., Anaplasma platys, Babesia vogeli, E. canis and Hepatozoon canis) are widespread and highly prevalent in some Mediterranean countries [2,4-6]. In highly endemic areas, the typical clinical presentation associated with individual TBDs in dogs may potentially be masked by simultaneous infections by multiple pathogens $[3,7]$.

Clearly, the risk of contracting TBDs is directly associated with the exposure to tick vectors. Therefore, the use of insecticides and repellents is currently considered the best option to prevent infections by tick-borne pathogens in dogs [8]. For instance, a spot-on formulation containing $10 \%$ imidacloprid and $50 \%$ permethrin (Advantix ${ }^{\circledR}$, Bayer HealthCare AG, Germany) has proven effective in protecting dogs against tick infestations under field conditions, as well as in preventing the transmission of selected tick-borne pathogens $[9,10]$. Recently, a collar containing 10\% imidacloprid and 4.5\% flumethrin (Seresto ${ }^{\circledR}$, Bayer Animal Health, Germany) was developed for use on dogs and cats. This product contains both repellent and insecticidal properties and has proven effective against fleas, ticks, mites and lice [11-15]. The imidacloprid/flumethrin collar was highly efficacious in curing animals living in communities highly infested with ticks and fleas and to prevent reinfestations for up to 8 months in a refuge with a history of unsuccessful environmental tick control [16].

Furthermore, recent laboratory studies have demonstrated the efficacy of this collar for the prevention of vector-borne pathogen transmission in both dogs and cats [17-20]. Specifically in dogs, this collar was effective in preventing the transmission of Babesia canis and $E$. canis by ticks $[18,19]$ as well as of Dipylidium caninum by the cat flea Ctenocephalides felis [17], under laboratory-controlled conditions. More recently, this collar was proven highly efficacious against $L$. infantum infection under field conditions [21]. Herein, we assessed the efficacy of this new device against tick and flea infestation as well as its efficacy against selected TBD pathogens (i.e., A. platys, B. vogeli, and $H$. canis) in young sheltered dogs living in an area where these infections are highly prevalent.

\section{Methods}

\section{Study design and study area}

A parallel group-designed, randomised, controlled efficacy field trial was conducted in a private shelter in the municipality of Putignano $\left(40^{\circ} 51^{\prime} \mathrm{N}, 17^{\circ} 7^{\prime} \mathrm{E}, 372 \mathrm{~m}\right.$ above sea level), province of Bari, Apulia region (southern Italy). The ectoparasite fauna and TBDs occurring in dogs in this shelter had been monitored over the previous three years $[1,10,22]$.
The design and experimental procedures used in this study were authorized by the Italian Ministry of Health (DGSA n ${ }^{\circ} 0001997 ; 04 / 02 / 2011$ ). Moreover, this study was conducted in accordance with the principles of Good Clinical Practice (VICH GL9 GCP, 2000) adopted by the Committee for Medicinal Products for Veterinary Use (CVMP) in the guidelines for the evaluation of the efficacy of antiparasitic substances against tick and flea infestation in dogs and cats (EMEA/CVMP/005/00, 2000).

\section{Animal management and care}

Dogs enrolled in this study were young dogs ( $\leq 6$ months old) of both sexes. Each dog received two doses of a vaccine against canine parvovirus, adenovirus type 2, distemper virus, Leptospira canicola and Leptospira icterohaemorrhagiae (Duramune ${ }^{\circledR}$ DAPPi + LC; Zoetis, Italy). In addition, all dogs were dewormed with a combination of praziquantel, pyrantel pamoate and fenbantel (Drontal plus ${ }^{\circledR}$; Bayer AG, Germany) at enrolment, and were examined every two months and treated whenever a faecal sample from a given cage was found positive for intestinal parasite eggs.

Dogs were housed in wire mesh enclosures (approx. $10 \times 20 \mathrm{~m}$ ) and fed commercial feed once per day, with water provided ad libitum. At each treatment time point (see below), the clinical status of each dog was recorded on individual forms. The application of other ectoparasiticides was not allowed during the study period except once (i.e., June 2011), when heavy tick infestation was recorded in untreated dogs.

\section{Enrolment and follow up assessments}

Dogs $(n=176)$ were enrolled into the study between March and May 2011. On day 0 each dog was microchipped, photographed, clinically examined and searched for ticks and fleas. All data, including sex, age, weight, and coat length, were recorded in appropriate individual files. Dogs were excluded from the study if under 7 weeks of age, if skin lesions were observed at the site of product application or if physical examination revealed a pre-existing disease.

The 176 enrolled dogs were randomly assigned to groups A (dogs collared at day 0 ) and B (untreated control dogs), but 52 of them died during the first weeks following enrolment due to parvoviral gastroenteritis (data not shown). The remaining dogs, reaching the first follow-up assessment (see below), consisted of 64 dogs in group A and 58 in group B. The homogeneity of the two groups in relation to sex, age, weight, and coat length was evaluated using chi-square test and one-way ANOVA.

Blood and serum samples were collected from all dogs included in the trial at the first (July 2011), second (September 2011), third (November 2011) and fourth (April 2012) follow-up assessments. 
All dogs were enrolled in the trial regardless of the results of the initial testing for the selected pathogens (see below). The inclusion of positive dogs in both groups was aimed at facilitating the circulation of pathogens within the dog population under examination, as well as at assessing the efficacy of the ectoparasiticide treatment at the subsequent follow-ups. At baseline (March-May 2011) collars were applied to all dogs from group A, according to the manufacturer's instructions: dogs $\leq 8 \mathrm{~kg}$ received a small collar and dogs $>8 \mathrm{~kg}$ received a large collar.

The collars were constantly worn and were replaced within two days in case of accidental losses. In addition, a new (large) collar was applied to dogs whose body weight increased to over $8 \mathrm{~kg}$. Finally, all collars were replaced 8 months after application, as per manufacturer's instructions. All occurrences (collar replacement, etc.) were recorded on the dog's individual file. At the end of the study period (April 2012), all collars were removed from group A dogs and in October 2012 a complete blood sample collection was performed to determine the incidence of TBDs amongst dogs previously collared (group A) or not collared (group B). The laboratory staff were blinded to treatment allocation of individual dogs, whereas the shelter staff were not blinded due to the visible collar.

\section{Estimation of flea and tick load}

Dogs were examined monthly for the presence of ticks and fleas by thumb counting, with examination of the following body regions: head, ears, breast-neck, thorax, abdomen, fore and back limbs, inter-digital areas, axilla, tail and inguinal area. The number and/or developmental stages of ticks and fleas detected in the above mentioned body sites were recorded on a separate form for each dog. Adult ticks were counted, whereas, due to the exceedingly large number of immature ticks, a visual estimate was made of the ticks located in the neck, thorax, abdomen, inter-digital and periocular areas and ears. Each site was considered as an independent unit of calculation. The load of immature ticks was grouped into the following four infestation classes:

- Low: <10 immature ticks;

- Medium: $<10 \mathrm{x}<50$ immature ticks;

- High: $<50 \mathrm{x}<100$ immature ticks;

- Very high: $\geq 100$ immature ticks.

Each of the four infestation classes was then multiplied by the number of body sites in which that parasitic load was estimated. Representative tick and flea specimens were identified based on morphology [23-25].

\section{Sample collection and diagnostic tests}

Blood samples were collected from the brachial or jugular veins in tubes with and without ethylenediaminetetraacetic acid (EDTA) anticoagulant. Room temperature coagulated blood was centrifuged at $1,678 \mathrm{~g}$ for $10 \mathrm{~min}$ prior to collecting the separated serum. Both the EDTA whole blood and serum samples were stored at $-20^{\circ} \mathrm{C}$ until tested (see below).

Antibodies against B. canis and E. FLUOBABESIA canis were detected using commercial IFAT kits (MegaScreen Fluobabesia, MegaCor GmbH, Austria, and Canine Ehrlichiosis FA Substrate Slide, VMRD, Pullmann, Washington, USA, respectively). Cytological examination of whole blood and buffy coat smears was performed, following staining with MGG Quick Stain (Bio Optica, Milan, Italy), for the presence of intracellular inclusions of the most common tick-borne pathogens of dogs.

For the detection of Ehrlichia and Anaplasma species, total DNA was extracted from EDTA-blood samples using MagAttract DNA Blood Mini M48 Kits and BioRobot M48 Workstation (Qiagen, Valencia, CA, USA). DNA samples were screened by amplification of a fragment of the groEL gene and a fragment of the $16 \mathrm{~S}$ rRNA gene, which are conserved across all Ehrlichia and Anaplasma species [26,27]. All positive samples were either sequenced directly (Genewiz, Inc., Research Triangle Park, NC) for speciation or subsequently tested by PCR assays designed for the detection of specific genetic markers for A. platys [28], A. phagocytophilum [29], and E. canis [10]. Babesia spp. DNA was amplified by PCR targeting a variable region of the 16S-like rRNA gene [30] and $H$. canis DNA by a PCR targeting a fragment of the $18 \mathrm{~S}$ rRNA gene [31], as described previously. Finally, Bartonella spp. was amplified by PCR targeting a fragment of the RNA polymerase b subunit ( $r p o B$ gene) as described elsewhere [32].

\section{Statistical analysis}

The minimum sample size $(n=49)$ was calculated using the software WinEpi (http://www.winepi.net/uk/index. htm), to estimate differences between proportions (i.e., incidence) from the two populations. The following assumptions were considered: (I) expected incidence in group $A=5 \%$; (II) expected incidence in group $B=15 \%$; (III) power $=85 \%$; (IV) level of confidence $=95 \%$. To accommodate potential losses during the study period, $\sim 60$ instead of 49 dogs were enrolled in each group.

The incidence of tick-borne pathogen infection was determined by Incidence Density rates (IDRs) [10,33], which was calculated as follows: IDRs = number of positive dogs/number of dog-months of follow-up (i.e., the number of months between the previous and the following assessment for each dog at risk of infection). Dogs were defined as "positive" if positive at any of the cytological, serological or PCR tests performed. Differences between IDRs in groups A and B were calculated using a Yates-corrected chi squared test. Dogs tested only once 
(e.g., those that died from parvoviral gastroenteritis) did not contribute to the calculation of incidence, whereas those sampled at least twice contributed to the IDR calculation during the number of months those dogs remained in the study. The post-treatment incidence was calculated considering the test results obtained in October 2012 in dogs that were negative both at enrolment and April 2012 prior to the removal of the collar.

The efficacy of the collar against tick-borne pathogens was calculated as follows: Efficacy $=[(\%$ of positive dogs in group B - \% of positive dogs in group A)/\% of positive dogs in group B] $\times 100$. For the calculation of the overall efficacy against tick-borne pathogens, $H$. canis was excluded, as this protozoon is not transmitted by tick bites. The efficacy of the collar against ticks (immature and adult stages) and fleas was calculated as follows: Efficacy $=$ (mean ectoparasites load on control dogs mean ectoparasites load on treated dogs)/(mean ectoparasites load in control dogs $) \times 100$. Collars were deemed effective against ectoparasites if the calculated efficacy, based on arithmetic and geometric means, was at least 90\% [34].

\section{Results}

Dogs from group A $(n=64)$ and group B $(n=58)$ were homogeneous $(p>0.05)$ in terms of number and individual characteristics (i.e., sex, age, weight, and coat length). At baseline, 25 (20.5\%) out of 122 dogs were positive for at least one tick-borne pathogen. Specifically, $17.2 \%$ of the dogs were infected with $A$. platys (i.e., $22 \%$ vs. $12 \%$ in groups A and B, respectively), $11.5 \%$ with $H$. canis (i.e., $10.9 \%$ vs. $9.1 \%$ ), $4.9 \%$ with Babesia spp. (4.7\% vs. $5.2 \%$ ) and $1.6 \%$ with Bartonella spp. (3.1 vs. $0 \%$ ). The pathogen prevalence at baseline between the two groups was not significantly different.

Two dogs were infected with Bartonella vinsonii subsp. berkhoffii genotype III and one dog each was infected with Bartonella henselae and Bartonella rochalimae. Coinfections by two or more pathogens were documented in 16 dogs (13.1\%), with seven dogs infected by $A$. platys and $H$. canis, two dogs with $A$. platys and $B$. vogeli and two dogs with $A$. platys and $B$. vinsonii subsp. berkhoffii genotype III. In three dogs, co-infection by three pathogens was diagnosed (data not shown). All dogs were negative for A. phagocytophilum and E. canis and only two dogs were PCR-positive for $B$. vinsonii subsp. berkhoffii genotype III and B. rochalimae in group B. Thus, the efficacy of the collar against these pathogens could not be calculated.

The IDRs for all tick-borne pathogens at all follow-up assessments were significantly higher in group B than in group A (Table 1), resulting in an overall efficacy of 91.6\%. For individual pathogens the efficacies were as follows: $100 \%$ for B. vogeli; $91.1 \%$ for A. platys; and 43.4\% for H. canis. At the end of the trial (April 2012),
110 dogs (61 from group A and 49 from group B) remained untreated and the post-treatment incidence, calculated in October 2012 (Table 2), indicates A. platys as the most common pathogen (incidence of $67.4 \%$ and $31 \%$ in groups $\mathrm{A}$ and $\mathrm{B}$, respectively), followed by $H$. canis $(9.6 \%$ and $47.8 \%)$, B. vogeli (5.1\% and $34.8 \%)$, and B. vinsonii subsp. berkhoffii genotype III ( $4.1 \%$ in group B only). Co-infections were detected in 25 (20.5\%) dogs, with eight dogs infected by $A$. platys and $H$. canis, eight with $B$. vogeli and $H$. canis, six with $A$. platys and $B$. vogeli, and three with $A$. platys, $B$. vogeli and $H$. canis.

The mean tick and flea load in both group A and B were comparable at baseline $(p>0.05)$. Conversely, the tick burden was significantly higher in control dogs $(\mathrm{p}<$ 0.01 ) throughout the study period, resulting in an overall efficacy against tick attachment of $99.7 \%$, ranging from 95.3 to $100 \%$ and from 98.2 to $100 \%$ against adult and immature ticks, respectively (Table 3 ). Importantly, only 11 ticks were collected from group A dogs during the whole study period, being nine alive (eight adults and 1 immature) and two dead adults. All ticks collected were morphologically identified as $R$. sanguineus group. Similarly, a $100 \%$ efficacy against fleas was calculated for each of the four assessments in which flea infestations were detected (Table 4). The mean flea loads in groups $A$ and $B$ were statistically different $(\mathrm{p}<0.01)$ only at the end of the season (September and November 2011). All fleas collected were morphologically identified as C. felis.

\section{Discussion}

This study investigated, for the first time under field conditions, the efficacy of a collar containing $10 \%$ imidacloprid and $4.5 \%$ flumethrin for the prevention of tick-borne pathogen infections in southern Europe, where a range of canine vector-borne diseases are endemic $[2,8]$. The pre-trial prevalence of tick-borne pathogen infections (e.g., A. platys, H. canis, Babesia spp., and B. vinsonii subsp. berkhoffii genotype III) in dogs, just prior to the beginning of the study, is in agreement with the results of previous investigations conducted in the same study site (see, for instance, Refs. $[4,9])$. Importantly, the role of sheltered dogs as reservoirs of certain pathogens for pet dogs and humans should be taken into account. For example, E. canis and A. platys are potential zoonotic pathogens $[1,35]$. These data highlight the need for the development of longlasting and cost-effective strategies for the prevention and control of canine vector-borne diseases [8]. In particular, the use of collars impregnated with acaricidal/ repellent compounds has recently provided promising results, indicating that long-lasting protection of dogs against the most common canine vector-borne diseases can be achieved in most instances $[5,18]$. Furthermore, 
Table 1 Incidence density rates (IDRs) of and efficacy (\%) against Anaplasma platys, Babesia vogeli and Hepatozoon canis infections in dogs from groups $A$ and $B$

\begin{tabular}{|c|c|c|c|c|c|c|c|c|c|}
\hline \multirow[t]{2}{*}{ Pathogen } & \multicolumn{2}{|c|}{ Number of dogs in the cohort } & \multicolumn{2}{|c|}{ Number of new infections } & \multicolumn{2}{|c|}{ Dog-months of follow-up } & \multicolumn{2}{|l|}{ IDRs } & \multirow[t]{2}{*}{ Efficacy } \\
\hline & A & B & $A$ & B & $A$ & B & $A$ & B & \\
\hline \multicolumn{10}{|c|}{ Anaplasma platys } \\
\hline Baseline & 64 & 58 & - & - & - & - & & & \\
\hline Follow-up 1 & 50 & 51 & 6 & 24 & 134.5 & 109.7 & 53.5 & 262.6 & \\
\hline Follow-up 2 & 44 & 23 & 4 & 18 & 115.7 & 59.8 & 41.5 & 361.2 & \\
\hline Follow-up 3 & 40 & 5 & 0 & 2 & 82.8 & 12.5 & 0 & 192.8 & \\
\hline Follow-up 4 & 40 & 3 & 0 & 0 & 162.8 & 12.5 & 0 & 0 & \\
\hline Total & & & 10 & 44 & 495.8 & 194.4 & 24.2 & 271.6 & $91.1 \%$ \\
\hline \multicolumn{10}{|l|}{ Babesia vogeli } \\
\hline Baseline & 64 & 58 & - & - & - & - & - & - & \\
\hline Follow-up 1 & 64 & 55 & 0 & 18 & 177.3 & 121.0 & 0 & 178.5 & \\
\hline Follow-up 2 & 63 & 35 & 0 & 1 & 165.7 & 91.7 & 0 & 13.1 & \\
\hline Follow-up 3 & 63 & 33 & 0 & 2 & 129. 8 & 68.0 & 0 & 35.3 & \\
\hline Follow-up 4 & 63 & 30 & 0 & 0 & 256.4 & 120.3 & 0 & 0.0 & \\
\hline Total & & & 0 & 21 & 729.2 & 401.0 & 0 & 62.9 & $100 \%$ \\
\hline \multicolumn{10}{|c|}{ Hepatozoon canis } \\
\hline Baseline & 64 & 58 & - & - & - & - & - & - & \\
\hline Follow-up 1 & 57 & 51 & 25 & 27 & 156.8 & 109.7 & 191.4 & 295.5 & \\
\hline Follow-up 2 & 32 & 23 & 10 & 8 & 84.5 & 59.3 & 142.1 & 161.8 & \\
\hline Follow-up 3 & 22 & 15 & 1 & 4 & 45.5 & 31.1 & 26.4 & 154.6 & \\
\hline Follow-up 4 & 21 & 11 & 0 & 3 & 85.5 & 45.7 & 0.00 & 78.9 & \\
\hline Total & & & 36 & 42 & 372.2 & 245.7 & 116.1 & 205.1 & $43.4 \%$ \\
\hline
\end{tabular}

collars may have advantages over other formulations (e.g., spot-on), including prolonged efficacy, steady concentration of the active compounds over its lifetime, and increased owner's treatment compliance (reviewed by [11]).

The efficacy of the imidacloprid/flumethrin collar has been previously evaluated against ticks (i.e., $R$. sanguineus, I. ricinus, I. scapularis, D. reticulatus and $D$. variabilis), mites (i.e. Sarcoptes scabiei), and lice (Trichodectes canis) under controlled conditions [11]. The results of this trial complement the outcomes of the

Table 2 Incidence of canine vector-borne pathogen infections in the former groups A (treated) and B (untreated), six months after the end of the study (October 2012)*

\begin{tabular}{llll}
\hline Pathogen & \multicolumn{2}{l}{ Positive/Total (\%) } & Total (\%) \\
\cline { 2 - 3 } & Former group A & Former group B & \\
\hline Anaplasma platys & $33 / 49(67.3)^{*}$ & $10 / 30(33.3)^{*}$ & $43 / 79(54.4)$ \\
Babesia vogeli & $3 / 59(5.1)$ & $5 / 34(14.7)$ & $8 / 93(8.6)$ \\
Bartonella spp. & $0 / 60(0.0)$ & $2 / 48(4.2)$ & $2 / 109(1.8)$ \\
Hepatozoon canis & $5 / 52(9.6)^{*}$ & $11 / 23(47.8)^{*}$ & $16 / 75(21.3)$ \\
\hline
\end{tabular}

*Statistically significant differences $(p<0.01)$ between former groups A and B. previous studies and further confirm the efficacy of this collar as a prophylactic tool against the transmission of tick-borne pathogens. Indeed, the high overall efficacy (99.7\%) against both adult and immature stages of ticks resulted in a high level of protection against $B$. vogeli and $A$. platys. The protection of dogs against ticks and their transmitted pathogens is important, particularly because these pathogens have the potential to lead to severe disease, especially in cases of co-infections $[7,10]$. Based on the results of the present study, the collar conferred $100 \%$ protection against B. vogeli, $91.1 \%$ against $A$. platys and $43.4 \%$ against $H$. canis. The observed differences in levels of protection against distinct pathogens are likely related to a range of factors inherent to the biology, ecology and transmission dynamics of such pathogens $[1,10]$. For instance, the low efficacy of the collar against $H$. canis infection registered in the present study was expected considering that this protozoan is not transmitted by tick bites, but orally when a dog ingests an infected tick [10,36]. Probably, $H$. canis infections detected in dogs from collared and control groups were associated with an increase in the number of $H$. canis-infected ticks in the environment during summer months, as previously documented [1,37]. While the 
Table 3 Mean counts of and efficacy against adult and immature stages of $R$. sanguineus group ticks during the treatment period

\begin{tabular}{|c|c|c|c|c|c|c|c|c|c|c|c|c|c|c|c|}
\hline \multirow{2}{*}{$\begin{array}{l}\text { Tick } \\
\text { stage }\end{array}$} & \multirow[t]{2}{*}{ Groups } & \multirow[t]{2}{*}{ Mean } & \multicolumn{9}{|l|}{2011} & \multicolumn{4}{|c|}{2012} \\
\hline & & & Day 0 & May & *Jun 1 & *Jun 2 & Jul & Aug & Sep & Oct & Nov & Jan & Feb & Mar & Apr \\
\hline \multirow[t]{6}{*}{ Adult } & \multirow[t]{2}{*}{ A } & Arithmetic & 37.5 & 0.2 & 0.2 & 0.1 & 0 & 0.1 & 0 & 0 & 0 & 0 & 0 & 0 & 0 \\
\hline & & Geometric & 19.3 & 0.1 & 0.1 & 0.1 & 0 & 0.1 & 0 & 0 & 0 & 0 & 0 & 0 & 0 \\
\hline & \multirow[t]{2}{*}{ B } & Arithmetic & 56.9 & 49.9 & 51.3 & 3.1 & 2.8 & 4.7 & 1.7 & 0.2 & 0.3 & 0.1 & 0.2 & 1.3 & 13.1 \\
\hline & & Geometric & 22.8 & 19.8 & 39.8 & 2.0 & 1.1 & 3.0 & 1.1 & 0.1 & 0.2 & 0.1 & 0.1 & 0.8 & 10.0 \\
\hline & \multicolumn{2}{|c|}{ Efficacy Ar. mean (\%) } & - & 99.6 & 99.6 & 96.7 & 100 & 97.9 & 100 & 100 & 100 & 100 & 100 & 100 & 100 \\
\hline & \multicolumn{2}{|c|}{ Efficacy Ge. mean (\%) } & - & 99.5 & 99.8 & 95.0 & 100 & 96.7 & 100 & 100 & 100 & 100 & 100 & 100 & 100 \\
\hline \multirow[t]{6}{*}{ Immature } & \multirow[t]{2}{*}{ A } & Arithmetic & 0.1 & 0 & 0 & 0 & 0 & 0 & 0 & 0 & 0 & 0 & 0 & 0 & 0 \\
\hline & & Geometric & 0.1 & 0 & 0 & 0 & 0 & 0 & 0 & 0 & 0 & 0 & 0 & 0 & 0 \\
\hline & \multirow[t]{2}{*}{ B } & Arithmetic & 0.1 & 1.8 & 4.3 & 106.3 & 0 & 0 & 0.3 & 0.1 & 0 & 0 & 0 & 0 & 4.5 \\
\hline & & Geometric & 0.1 & 0.8 & 2.8 & 25.7 & 0 & 0 & 0.2 & 0.1 & 0 & 0 & 0 & 0 & 2.6 \\
\hline & \multicolumn{2}{|c|}{ Efficacy Ar. mean (\%) } & - & 100 & 100 & 100 & n.a. & n.a. & 100 & 100 & n.a & n.a & n.a & n.a & 100 \\
\hline & \multicolumn{2}{|c|}{ Efficacy Ge. mean (\%) } & - & 100 & 100 & 100 & n.a & n.a & 100 & 100 & n.a & n.a & n.a & n.a & 100 \\
\hline
\end{tabular}

*Sampling occurred in monthly intervals. As it was conducted at beginning and end of June, June appears twice.

Abbreviations: n.a. not applied, Ar. arithmetic, Ge. geometric.

efficacy of the collar against tick infestations (>99\%) impacts on the likelihood of a dog ingesting a $H$. canisinfected tick, our findings suggest that integrated control strategies focused on dogs and the environment may be warranted. For instance, the level of tick infestation in the environment might be particularly high in dog shelters; therefore, the application of insecticides in the environment may be necessary to control high tick burdens in this particular situation.

Molecular evidence of $A$. platys infection has been reported in a range of tick species [38-40], even if the role of ticks as vectors of this bacterium has yet to be confirmed [41]. Remarkably, the very small number of A. platys infections in dogs from group A demonstrates the efficacy of the imidacloprid/flumethrin collar against this pathogen and, indirectly, reinforces the hypothesis that $R$. sanguineus group ticks may transmit $A$. platys to dogs, especially considering the high incidence of infection during the post-treatment phase recorded herein.
Certainly, the efficacy of the collar against $R$. sanguineus group ticks may potentially help in preventing infection with pathogens other than $B$. vogeli and $A$. platys, such as E. canis, as demonstrated under laboratory conditions [19]. In fact, the overall efficacy against both adult and immature ticks recorded in this study is relevant, considering that most pathogens harboured by $R$. sanguineus group ticks are passed transstadially (e.g., $H$. canis and E. canis), while only a few are transmitted transovarially (e.g., B. vogeli and $R$. conorii) [42-44].

\section{Conclusions}

The long-term protection conferred by the imidacloprid/ flumethrin collar against fleas, ticks and tick-borne pathogens is in agreement with previous studies, in which the efficacy of the collar was ascertained for up to 8 months [11]. However, it should be noted that, upon removal of the collars, the prevalence of tick-borne infections in dogs from group A increased dramatically

Table 4 Mean counts of Ctenocephalides felis and the efficacy during the treatment period

\begin{tabular}{|c|c|c|c|c|c|c|c|c|c|c|c|c|c|c|}
\hline \multirow[t]{2}{*}{ Group } & \multirow[t]{2}{*}{ Mean } & \multicolumn{9}{|l|}{2011} & \multicolumn{4}{|c|}{2012} \\
\hline & & Day 0 & May & *Jun 1 & *Jun 2 & Jul & Aug & Sep & Oct & Nov & Jan & Feb & Mar & Apr \\
\hline \multirow[t]{2}{*}{$\bar{A}$} & Arithmetic & 0.7 & 0 & 0 & 0 & 0 & 0 & 0 & 0 & 0 & 0 & 0 & 0 & 0 \\
\hline & Geometric & 0.2 & 0 & 0 & 0 & 0 & 0 & 0 & 0 & 0 & 0 & 0 & 0 & 0 \\
\hline \multirow[t]{2}{*}{ B } & Arithmetic & 1.3 & 0 & 0 & 0 & 0 & 0.1 & 0.2 & 0 & 0.4 & 0 & 0 & 0 & 0.2 \\
\hline & Geometric & 0.5 & 0 & 0 & 0 & 0 & 0.1 & 0.1 & 0 & 0.2 & 0 & 0 & 0 & 0.1 \\
\hline \multicolumn{2}{|c|}{ Efficacy Ar. mean (\%) } & - & n.a. & n.a. & n.a. & n.a. & 100 & 100 & n.a. & 100 & n.a. & n.a. & n.a. & 100 \\
\hline \multicolumn{2}{|c|}{ Efficacy Ge. mean (\%) } & - & n.a. & n.a. & n.a. & n.a. & 100 & 100 & n.a & 100 & n.a & n.a. & n.a & 100 \\
\hline
\end{tabular}

*Sampling occurred in monthly intervals. As it was conducted at beginning and end of June, June appears twice. Abbreviations: n.a. not applied, Ar. arithmetic, Ge. geometric. 
(e.g., A. platys, up to $67.4 \%$ ). This finding is consistent with previous observations [10] and advocates the need for continued control of dogs against tick infestation, so as to prevent tick-borne pathogen transmission. Indeed, the availability of safe and effective acaricidal and/or repellent products will undoubtedly assist in the establishment of long-term control programs to prevent transmission of vector-borne diseases to dogs and may also help to reduce potential risks for human health.

\section{Competing interests}

The authors declare that they have no competing interests.

\section{Authors' contributions}

DO and DS conceived the research. DO, FDT, DS, GC, CC, EB, AG, RR wrote the first draft, contributed with data analysis and interpretation, and revised the manuscript. DO, FDT, AG, RR, GD, AD, DD, RL, VT worked in the field on sample collection and animal examination $S D, M S L, V T, B Q, V L$ performed diagnostic analyses. GC performed the statistical analyses. All authors read and approved the final version of the manuscript.

\section{Acknowledgments}

For the field work we are grateful to Sabrina Gallo and Angelo Carucci (practitioners at the Centro Veterinario "S. Francesco", Putignano, Bari) and to Mrs. Irene Troilo.

\section{Author details}

${ }^{1}$ Department of Veterinary Medicine, University of Bari, Bari, Valenzano, Italy. ${ }^{2}$ Current address: Department of Immunology, Aggeu Magalhães Research Center, Recife, Pernambuco, Brazil. ${ }^{3}$ Istituto Zooprofilattico Sperimentale delle Venezie, Padova, Legnaro, Italy. ${ }^{4}$ Center for Biodiscovery and Molecular Development of Therapeutics, James Cook University, Cairns, Australia. ${ }^{5}$ Intracellular Pathogens Research Laboratory, Center for Comparative Medicine and Translational Research, College of Veterinary Medicine, North Carolina State University, Raleigh, NC, USA. ${ }^{6}$ Bayer Animal Health GmbH, Leverkusen, Germany.

Received: 3 July 2013 Accepted: 18 August 2013

Published: 23 August 2013

\section{References}

1. Dantas-Torres F, Chomel BB, Otranto D: Ticks and tick-borne diseases: a One Health perspective. Trends Parasitol 2012, 28:437-446.

2. Otranto D, Dantas-Torres F: Canine and feline vector-borne diseases in Italy: current situation and perspectives. Parasit Vectors 2010, 3:2

3. De Tommasi AS, Otranto D, Dantas-Torres F, Capelli G, Breitschwerdt EB, de Caprariis D: Are vector-borne pathogen co-infections complicating the clinical presentation in dogs? Parasit Vectors 2013, 6:97.

4. Sparagano OA, de Vos AP, Paoletti B, Cammà C, de Santis P, Otranto D, Giangaspero A: Molecular detection of Anaplasma platys in dogs using polymerase chain reaction and reverse line blot hybridization. J Vet Diagn Invest 2003, 15:527-534.

5. Otranto D, Dantas-Torres F, Brianti E, Traversa D, Petrić D, Genchi C, Capelli G: Vector-borne helminths of dogs and humans in Europe. Parasit Vectors 2013, 6:16.

6. Pennisi MG, Caprì A, Solano-Gallego L, Lombardo G, Torina A, Masucci M: Prevalence of antibodies against Rickettsia conorii, Babesia canis, Ehrlichia canis, and Anaplasma phagocytophilum antigens in dogs from the Stretto di Messina area (Italy). Ticks Tick Borne Dis 2012, 3:315-318.

7. de Caprariis D, Dantas-Torres F, Capelli G, Mencke N, Stanneck D, Breitschwerdt EB, Otranto D: Evolution of clinical, haematological and biochemical findings in young dogs naturally infected by vector-borne pathogens. Vet Microbiol 2011, 149:206-212

8. Otranto D, Dantas-Torres F, Breitschwerdt EB: Managing canine vector-borne diseases of zoonotic concern: part two. Trends Parasitol 2009, 25:228-235.

9. Otranto D, Paradies $P$, Testini $G$, Latrofa MS, Weigl S, Cantacessi C, Mencke N, de Caprariis D, Parisi A, Capelli G, Stanneck D: Application of $10 \%$ imidacloprid/50\% permethrin to prevent Ehrlichia canis exposure in dogs under natural conditions. Vet Parasitol 2008, 153:320-328.
10. Otranto D, de Caprariis D, Lia RP, Tarallo V, Lorusso V, Testini G, DantasTorres F, Latrofa S, Diniz PP, Mencke N, Maggi RG, Breitschwerdt E, Capelli G, Stanneck D: Prevention of endemic canine vector-borne diseases using imidacloprid $10 \%$ and permethrin $50 \%$ in young dogs: a longitudinal field study. Vet Parasitol 2010, 172:323-332.

11. Stanneck D, Rass J, Radeloff I, Kruedewagen E, Le Sueur C, Hellmann K, Krieger K: Evaluation of the long-term efficacy and safety of an imidacloprid $10 \%$ /flumethrin $4.5 \%$ polymer matrix collar (Seresto ${ }^{\oplus}$ ) in dogs and cats naturally infested with fleas and/or ticks in multicentre clinical field studies in Europe. Parasit Vectors 2012, 5:66.

12. Stanneck D, Kruedewagen EM, Fourie JJ, Horak IG, Davis W, Krieger KJ: Efficacy of an imidacloprid/flumethrin collar against fleas and ticks on cats. Parasit Vectors 2012, 5:82.

13. Stanneck D, Ebbinghaus-Kintscher U, Schoenhense E, Kruedewagen EM, Turberg A, Leisewitz A, Jiritschka W, Krieger KJ: The synergistic action of imidacloprid and flumethrin and their release kinetics from collars applied for ectoparasite control in dogs and cats. Parasit Vectors 2012, 5:73.

14. Horak IG, Fourie JJ, Stanneck D: Efficacy of slow-release collar formulations of imidacloprid/flumethrin and deltamethrin and of spot-on formulations of fipronil/(s)- methoprene, dinotefuran/pyriproxyfen/permethrin and (s) methoprene/amitraz/fipronil against Rhipicephalus sanguineus and Ctenocephalides felis felis on dogs. Parasit Vectors 2012, 5:79.

15. Smith WM, Ahlstrom LA, Rees R: Long-term efficacy of an imidacloprid 10\%/ flumethrin $4.5 \%$ polymer matrix collar (Seresto ${ }^{\oplus}$, Bayer) against the Australian paralysis tick (Ixodes holocyclus) in dogs. Parasitol Res 2013, 112:S1-S10.

16. Brianti E, Falsone L, Napoli E, Prudente C, Gaglio G, Giannetto S: Efficacy of a combination of $10 \%$ imidacloprid and $4.5 \%$ flumethrin (Seresto ${ }^{\circledR}$ ) in slow release collars to control ticks and fleas in highly infested dog communities. Parasit Vectors 2013, 6:210.

17. Fourie JJ, Crafford D, Horak IG, Stanneck D: Prophylactic treatment of flea infested cats with an imidacloprid/flumethrin collar to forestall infection with Dipylidium caninum. Parasit Vectors 2012, 5:151

18. Fourie JJ, Stanneck D, Jongejan F: Prevention of transmission of Babesia canis by Dermacentor reticulatus ticks to dogs treated with an imidacloprid/flumethrin collar. Vet Parasitol 2013, 192:273-278.

19. Stanneck D, Fourie JJ: Imidacloprid $10 \%$ / flumethrin $4.5 \%$ collars (Seresto $\left({ }^{\odot}\right.$ ), Bayer) successfully prevent long-term transmission of Ehrlichia canis by infected Rhipicephalus sanguineus ticks to dogs. Parasitol Res 2013, 112(Suppl 1):21-32

20. Lappin MR, Davis WL, Hawley JR, Brewer M, Morris A, Stanneck D: A flea and tick collar containing 10\% imidacloprid and $4.5 \%$ flumethrin prevents flea transmission of Bartonella henselae in cats. Parasit Vectors 2013, 6:26.

21. Otranto D, Dantas-Torres F, de Caprariis D, Di Paola G, Tarallo VD, Latrofa MS, Lia RP, Annoscia G, Breitshwerdt EB, Cantacessi C, Capelli G, Stanneck D: Prevention of canine leishmaniosis in a hyper-endemic area using a combination of 10\% imidacloprid/4.5\% flumethrin. PLOS One 2013, 8:e56374.

22. Lorusso V, Dantas-Torres F, Lia RP, Tarallo VD, Mencke N, Capelli G, Otranto D: Seasonal dynamics of the brown dog tick, Rhipicephalus sanguineus, on a confined dog population in Italy. Med Vet Entomol 2010, 24:309-315.

23. Berlinguer G: Studio monografico. Roma: Aphaniptera d'Italia; 1964.

24. Walker JB, Keirans JE, Horak IG: Genus Rhipicephalus (Acari, Ixodidae). A guide to the brown ticks of the world. Cambridge: Cambridge University Press; 2000.

25. Dantas-Torres F, Latrofa MS, Annoscia G, Giannelli A, Parisi A, Otranto D: Morphological and genetic diversity of Rhipicephalus sanguineus sensu lato from the New and Old Worlds. Parasit Vectors 2013, 6:213.

26. Barber RM, Li Q, Diniz PPVP, Porter BF, Breitschwerdt EB, Claiborne MK, Birkenheuer AJ, Levine JM, Levine GJ, Chandler K, Kenny P, Nghiem P, Wei S, Greene CE, Kent M, Platt SR, Greer K, Schatzberg SJ: Evaluation of brain tissue or cerebrospinal fluid with broadly reactive polymerase chain reaction for Ehrlichia, Anaplasma, spotted fever group Rickettsia, Bartonella, and Borrelia species in canine neurological diseases (109 Cases). J Vet Intern Med 2010, 24:372-378.

27. Eddlestone SM, Diniz PPVP, Neer TM, Gaunt SD, Corstvet R, Cho D, Hosgood G, Hegarty B, Breitschwerdt ED: Doxycycline clearance of experimentally induced chronic Ehrlichia canis infection in dogs. J Vet Intern Med 2007, 21:1237-1242.

28. Beall MJ, Chandrashekar R, Eberts MD, Cyr KE, Diniz PPVP, Mainville C, Hegarty BC, Crawford JM, Breitschwerdt EB: Serological and molecular prevalence of Borrelia burgdorferi, Anaplasma phagocytophilum, and Ehrlichia species in dogs from Minnesota. Vector Borne Zoonotic Dis 2008, 8:455-464. 
29. Scorpio DG, Akkoyunlu M, Fikrig E, Dumler JS: CXCR2 block-ade influences Anaplasma phagocytophilum propagation but not histopathology in the mouse model of human granulocytic anaplasmosis. Clin Diagn Lab Immunol 2004, 11:963-968.

30. Kordick SK, Breitschwerdt EB, Hegarty BC, Southwick KL, Colitz CM, Hancock SI, Bradley JM, Rumbough R, Mcpherson JT, Mac-Cormack JN: Coinfection with multiple tick-borne pathogens in a walker hound kennel in North Carolina. J Clin Microbiol 1999, 37:2631-2638.

31. Inokuma H, Okuda M, Ohno K, Shimoda K, Onishi T: Analysis of the $18 \mathrm{~S}$ rRNA gene sequence of a Hepatozoon detected in two Japanese dogs. Vet Parasitol 2002, 106:265-271.

32. Diniz PP, Maggi RG, Schwartz DS, Cadenas MB, Bradley JM, Hegarty B, Breitschwerdt EB: Canine bartonellosis: serological and molecular prevalence in Brazil and evidence of co-infection with Bartonella henselae and Bartonella vinsonii subsp. berkhoffii. Vet Res 2007, 38:697-710.

33. Moreira ED Jr, de Souza VM M, Sreenivasan M, Nascimento EG, Pontes de Carvalho L: Assessment of an optimized dog-culling program in the dynamics of canine Leishmania transmission. Vet Parasitol 2004, 6:245-252.

34. Marchiondo AA, Holdsworth PA, Fourie LJ, Rugg D, Hellmann K, Snyder DE, Dryden MW: World Association for the Advancement of Veterinary Parasitology (W.A.A.V.P.) second edition: guidelines for evaluating the efficacy of parasiticides for the treatment, prevention and control of flea and tick infestations on dogs and cats. Vet Parasitol 2013, 194:84-97.

35. Maggi RG, Mascarelli PE, Havenga LN, Naidoo V, Breitschwerdt EB: Coinfection with Anaplasma platys, Bartonella henselae and Candidatus Mycoplasma haematoparvum in a veterinarian. Parasit Vectors 2013, 6:103.

36. Baneth G: Perspectives on canine and feline hepatozoonosis. Vet Parasitol 2011, 181:3-11.

37. Giannelli A, Ramos RA, Di Paola G, Mencke N, Dantas-Torres F, Baneth G, Otranto D: Transstadial transmission of Hepatozoon canis from larvae to nymphs of Rhipicephalus sanguineus. Vet Parasitol 2013, 196:1-5.

38. Inokuma H, Beppu T, Okuda M, Shimada Y, Sakata Y: Epidemiological survey of Anaplasma platys and Ehrlichia canis using ticks collected from dogs in Japan. Vet Parasitol 2003, 115:343-348.

39. Parola P, Cornet JP, Sanogo YO, Miller RS, Thien HV, Gonzalez JP, Raoult D, Telford R, Wongsrichanalai C: Detection of Ehrlichia spp., Anaplasma spp., Rickettsia spp., and other eubacteria in ticks from the Thai-Myanmar border and Vietnam. J Clin Microbiol 2003, 41:1600-1608.

40. Shaw SE, Day MJ, Birtles RJ, Breitschwerdt EB: Tick-borne infectious diseases of dogs. Trends Parasitol 2001, 17:74-80.

41. Simpson RM, Gaunt SD, Hair JA, Kocan KM, Henk WG, Casey HW: Evaluation of Rhipicephalus sanguineus as a potential biologic vector of Ehrlichia platys. Am J Vet Res 1991, 52:1537-1541.

42. Otranto D, Capelli G, Genchi C: Changing distribution patterns of canine vector borne diseases in Italy: leishmaniosis vs. dirofilariosis. Parasit Vectors 2009, 1:S2.

43. Socolovschi C, Gaudart J, Bitam I, Huynh TP, Raoult D, Parola P: Why are there so few Rickettsia conorii conorii-infected Rhipicephalus sanguineus ticks in the wild? PLoS Negl Trop Dis 2012, 6:e1697.

44. Dantas-Torres F: Biology and ecology of the brown dog tick, Rhipicephalus sanguineus. Parasit Vectors 2010, 3:26.

\section{Submit your next manuscript to BioMed Central and take full advantage of:}

- Convenient online submission

- Thorough peer review

- No space constraints or color figure charges

- Immediate publication on acceptance

- Inclusion in PubMed, CAS, Scopus and Google Scholar

- Research which is freely available for redistribution

Submit your manuscript at www.biomedcentral.com/submit 